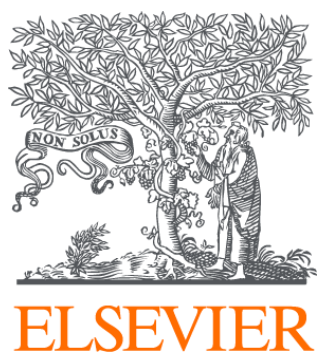

Since January 2020 Elsevier has created a COVID-19 resource centre with free information in English and Mandarin on the novel coronavirus COVID-

19. The COVID-19 resource centre is hosted on Elsevier Connect, the company's public news and information website.

Elsevier hereby grants permission to make all its COVID-19-related research that is available on the COVID-19 resource centre - including this research content - immediately available in PubMed Central and other publicly funded repositories, such as the WHO COVID database with rights for unrestricted research re-use and analyses in any form or by any means with acknowledgement of the original source. These permissions are granted for free by Elsevier for as long as the COVID-19 resource centre remains active. 
In Britain there is an intractable-pain society and a few pain centres to which patients with pain problems can be referred. This goes some way in meeting Dr Freed's plea that his fellow doctors must be enlightened. However, there is still an urgent need for more teaching and discussion about the treatment of pain in our medical schools and hospitals. It is no use just saying to a distracted patient "You should not be having so much pain," we have to do something about it.

16 Cresswell Gardens,

London SW5.

SIR,-Pain is described by Dr Freed in a way that makes the size of nerve and position, and type, of damage important. The concept of pain threshold is necessary too. It is also true that pain from nerve damage, and especially nerve-root damage, diminishes with time, but can suddenly be exacerbated apparently by a fall in barometric pressure.

The greatest service that I have received was to be reassured that the pain would get better, although all my introspection from any medical training seemed to contradict that. Fortunately the adviser was a doctor.

In my experience the " horrors of the night" were directly attributable to the hallucinatory drugs.

21 Upper Lattimore Road,

St. Albans AL1 3UD.

M. J. JAMESON.

\section{ROTAVIRUSES OF MAN AND ANIMALS}

SIR,-Following your editorial (Feb. 1, p. 257) on a possible role for coronaviruses in human diarrhoa, the following serological study may be of interest.

In 1973, human sera were tested for serum neutralising antibody to the reo-like calf diarrhcea agent. One test group was from an urban population; the other test group had been exposed to cattle and/or calf vaccine. The titres of both groups were similar. Recently, 34 sera from the above animal-contact group and 32 sera from the urban group were tested for serum neutralising antibody to a calf diarrhœa coronavirus. Titres ranged from 8 to greater than 181. Postvaccination calf sera titres range from 22 to 323 . In addition, calf diarrhœa coronavirus does not serologically cross-react with human respiratory coronavirus prototype $229 \mathrm{E}$, further suggesting the existence of an enteric coronavirus in man.

College of Agriculture,

University of Nebraska,

Agricultural Experiment Station,

Lincoln, Nebraska 68503, U.S.A.

\section{RICHARD SHARPEE} Charles A. MEBus.

\section{VIRUSES IN WATER}

SiR,-Dr Fuller's letter (Nov. 30, p. 1318) prompts me to comment on viruses in water in Canada. In most parts of Canada the severe winters necessitate anaerobic sludge digestion. During anaerobic digestion there is considerable formation of unstable reduced breakdown products with formation of methane and other gases. The effluent is then forcibly aerated and finally chlorinated before discharge, usually into a river system.

McLean and Brown ${ }^{1}$ demonstrated that persistence of virus in water is enhanced by lack of movement. It seems that the constant production of gases followed by forcible aeration produces a state too turbulent for virus survival, and chlorination ( 1 p.p.m.) is an additional safeguard.

Vancouver alone among the major cities of Canada has a temperature equable enough to permit aerobic effluent treatment on a year-round basis. Weekly samples of Vancouver effluent were taken over a period of eighteen

1. Mclean, D. M., Brown, J. R. Hlth Lab. Sci. 1966, 3, no. 3. months, in order to investigate its virus content. From May until October samples were taken both before and after chlorination ( 0.5 p.p.m. in the final effluent). During the other months the sewage was too diluted by the heavy seasonal rain for chlorination to have any effect. The final effluent was invariably found to be viricidal of itself; this viricidal effect was enhanced by chlorination and concentration, and weakened when rain diluted the effluent overly. At no time, however, was it non-viricidal, nor was any enterovirus isolated from it.

McLean ${ }^{2}$ demonstrated the viricidal effect of sea-water. Vancouver final effluent is discharged into the estuarine waters of the Fraser river, and these are of course brackish. The salinity varies with the tide, and it is hoped to investigate the effect of the tide on the viricidal qualities of final effluent, chlorinated or otherwise.

\section{Division of Medical Microbiology, \\ University of British Columbia, \\ Vancouver V6T 1W5,} Canada.

ANNE M. BURSEWICZ.

\section{AMINES, ANTICONVULSANTS, AND EPILEPSY}

SIR,-Some work of ours ${ }^{3}$ may, in part, explain the findings of Dr Chadwick and others (March 1, p. 473) on the raised concentrations of the 5-hydroxytryptamine (5-H.T.) metabolite, 5-hydroxyindoleacetic acid (5-H.I.A.A.), in the cerebrospinal fluid (C.S.F.) of epileptic patients treated with phenytoin.

The administration to rats of one dose of phenytoin (75 mg. per kg. intraperitoneally) enhanced the hyperactivity syndrome which results from increased 5-H.T. synthesis and functional activity in the brain and which is produced by injection of tranylcypromine and L-tryptophan. ${ }^{4}$ Phenytoin, one dose, did not alter the concentration of brain 5-H.T., the rate of 5-H.T. synthesis, or the post-synaptic responses to the administration of a 5-H.T. agonist. We have suggested that acute phenytoin administration alters the amount of 5-H.T. available for release and functional activity at the nerve ending. However, when phenytoin ( $75 \mathrm{mg}$. per kg.) was given twice daily for 2 days the rate of 5-H.T. synthesis increased by $100 \%$ without any alteration of its steady-state concentration in the brain.

Similar changes in 5-H.T. synthesis and functional activity have been observed in rats after acute and longer-term lithium ${ }^{5}$ and there are reports of raised C.S.F. 5-H.I.A.A. concentrations in patients on lithium. ${ }^{6,7}$ It seems very likely, therefore, that the changes in C.S.F. 5-H.I.A.A. reflect a more rapid turnover of 5-H.T. in the central nervous system of patients treated with phenytoin.

While the doses we used in rats were high compared with the usual therapeutic dose, it is of interest that Chadwick et al. found the largest increases in C.S.F. 5-H.I.A.A. in patients clinically intoxicated. In our studies of mephenytoin, ethotoin, ethosuximide, phenacemide, phenytoin, carbamazepine, and phenobarbitone, only phenytoin produced the pharmacological effects reported above. It appears that all the patients in whom Chadwick et al. found increased C.S.F. 5-H.I.A.A. concentrations were receiving this drug.

Lithium has not been shown to have definite anticonvulsant activity, ${ }^{8}$ but it produces changes in 5-H.T. metabolism similar to those produced by phenytoin. Pheno-

2. McLean, D. M., Brown, J. R. Laboratory Section, Canadian Public Health Association, December, 1967

3. Green, A. R., Grahame-Smith, D. G. Neuropharmacology, 1975, 14, 107.

4. Grahame-Smith, D. G. F. Neurochem. 1971, 18, 1053.

5. Grahame-Smith, D. G., Green, A. R. Br. F. Pharmac. 1974, 52, 19

6. Mendels, J. Lancet, 1971, i, 342.

7. Wilk, S., Shopsin, B., Gershon, S., Suhl, M. Nature, 1972, 235, 440.

8. Perkinson, E., Ruckart, R., De Vanzo, J. P. Proc. Soc. exp. Biol. Med. 1969, 131, 685. 